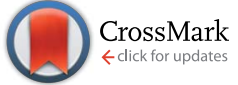

Cite this: RSC Adv., 2017, 7, 13257

Received 5th January 2017

Accepted 21st February 2017

DOI: 10.1039/c7ra00144d

rsc.li/rsc-advances

\section{Design and synthesis of dodecahedral carbon nanocages incorporated with $\mathrm{Fe}_{3} \mathrm{O}_{4} \dagger$}

\author{
Siyuan Xiang, ${ }^{a}$ Yanhong Shi, ${ }^{\mathrm{b}}$ Kai Zhang, ${ }^{\star a}$ Yixin Chen, ${ }^{a}$ Rui Ge, ${ }^{a} \mathrm{Ce} \mathrm{Wu},{ }^{a}$ Haizhu Sun ${ }^{\mathrm{b}}$ \\ and Bai Yang ${ }^{a}$
}

Novel dodecahedral carbon nanocages (NCs) modified with $\mathrm{Fe}_{3} \mathrm{O}_{4}$ nanoparticles $\left(\mathrm{Fe}_{3} \mathrm{O}_{4} / \mathrm{C} \mathrm{NCs}\right)$ were constructed by utilizing a zeolitic imidazolate framework (ZIF-8) as the template and polydopamine (PDA) as the carbon source. The obtained nanocages not only display specific morphology with controllable feature structures, but also possess a large surface area and inner cavity. This unique structure of the nanocages and special synthesis approach make $\mathrm{Fe}_{3} \mathrm{O}_{4}$ NPs homogenously distributed in the system, which further enriched the function of the carbon nanocages. Due to the integrated functional nanoparticles and large interior of such specific structures, the as-prepared $\mathrm{Fe}_{3} \mathrm{O}_{4} / \mathrm{C} \mathrm{NCs}$ are further used as anode materials in lithium ion batteries (LIBs), which exhibit high activity in lithiation/delithiation cycling process and stable capacity retention. The nanocages we prepared may provide a train of thought to construct a series of hollow carbon nanostructures with functional materials incorporated.

\section{Introduction}

Hollow nanocages have attracted great attention because of their unique properties such as low density, high surface area, shell permeability, chemical and physical stability, etc. ${ }^{\mathbf{1 , 2}}$ They have successfully found applications in many fields ranging from delivery vehicles to batteries. ${ }^{3-5}$ Various nanocages have been prepared by template methods, supramolecular assembly, galvanic replacement, etc. $^{6-8}$ However, there still exist some issues to be addressed, such as complicated synthesis, tedious posttreatment procedures, high cost, etc. In addition, nanocages with non-sphere shapes and regular interiors are still difficult to obtain. These unique nanocages are of particular interests due to their special physical properties and can serve as building blocks for assembly into hierarchical synthetic architectures. Moreover, they bring advantages that aren't able to be achieved through traditional round shapes driven by surface-tension. ${ }^{9}$ Therefore, it is significant to obtain nanocages with specific morphology and controllable properties.

To solve these problems, researchers have developed approaches to synthesize anisotropic nanocages with different structures. For instance, Lou's group successfully established a synthetic approach of inorganic nanocages via a templating method.,9-12 In addition, we exploited a novel 'chelation

${ }^{a}$ State Key Laboratory of Supramolecular Structure and Materials, College of Chemistry, Jilin University, Changchun 130012, People's Republic of China. E-mail: zk@jlu.edu.cn

${ }^{b}$ Faculty of Chemistry, Northeast Normal University, Changchun 130024, China $\dagger$ Electronic supplementary information (ESI) available: Detail characterization of $\mathrm{Fe}_{3} \mathrm{O}_{4}$ NPs and the obtained $\mathrm{Fe}_{3} \mathrm{O}_{4} / \mathrm{C}$ NCs; lithium storage properties of C NCs. See DOI: $10.1039 / \mathrm{c} 7 \mathrm{ra00144d}$ competition induced polymerization' (CCIP) method to prepare hollow polydopamine nanocontainers. ${ }^{13}$ These nanocages not only possess the inherent properties of materials, but also exhibit some new functions which are derived from the new hollow structure. Moreover, after annealing under inert gas, these polymer-based hollow structures can be further transformed into carbon nanocages.

Nowadays carbon materials are more and more popular due to their good electronic conductivity, high availability and cost efficiency and shown great potential in many fields like lithium-ion batteries (LIBs). ${ }^{14-16}$ In order to meet the ever-growing demands of market, anode materials are no longer limited to traditional graphite electrodes (theoretical capacity of $370 \mathrm{~mA} \mathrm{~h} \mathrm{~g}^{-1}$ ), various carbon materials with different structures were prepared. ${ }^{\mathbf{1 7 - 1 9}}$ Moreover, nanocomposites integrated carbon with other materials possessing higher theoretical capacity (such as metal oxide, $\mathrm{Fe}_{3} \mathrm{O}_{4}$, $924 \mathrm{~mA} \mathrm{~h} \mathrm{~g}^{-1}$ ) were also investigated..$^{\mathbf{1 8 0}, 22}$ Compared to the solid one, carbon nanostructures with hollow interior have shown much more advantages in LIBs since they will facilitate electrolyte transportation, lithium ion diffusion, provide more space to alleviate the stain arising from $\mathrm{Li}$ insertion/removal and enlarge the surface to volume ratio, resulting in faster reaction kinetics and higher specific capacity. ${ }^{20-22}$ For example, Xiong group has prepared a polyhedral carbon nanocages by carbonizing ZIF8@ZIF-67 core-shell crystals. Such bi-metal embedded N-doped nanocages show an initial discharge capacity of $809 \mathrm{~mA} \mathrm{~h} \mathrm{\textrm {g } ^ { - 1 }}$ and a capacity retention of $702 \mathrm{~mA} \mathrm{~h} \mathrm{~g}^{-1}$ after 400 cycles at a current density of $0.2 \mathrm{~A} \mathrm{~g}^{-1} \cdot{ }^{23}$ Despite of the achieved progress, it is still very important for us to construct more novel functional nanostructures as anode materials for LIBs. 
In this work, a novel kind of dodecahedral carbon nanocages was successfully constructed. The method we developed exactly provided an effective way to prepare a unique carbon nanocage structure by using zeolitic imidazolate framework (ZIF-8) as template and polydopamine as carbon resource. The obtained carbon nanocages not only maintain the shape of ZIF-8 with highly uniform shells and tunable sizes, but also make it easy to introduce functional nanoparticles $\left(\right.$ e.g. $\mathrm{Fe}_{3} \mathrm{O}_{4}$ NPs in this work, named $\mathrm{Fe}_{3} \mathrm{O}_{4} / \mathrm{C} \mathrm{NCs}$ ) into the system. The carbon nanocage matrix has more space for the volume expansion of $\mathrm{Fe}_{3} \mathrm{O}_{4} \mathrm{NPs}$ due to their large inner cavity and surface area, as well as provide a continue network for ion and electron transfer by embedding nanoparticles into the system. Moreover, N-doped is easily realized by choosing PDA as carbon resource, further improving the conductivity of the nanocages. The electrochemical performance as anode materials of LIBs was evaluated. The results show good cyclic performance and stability, indicating their promising application in energy fields.

\section{Experimental section}

\subsection{Materials}

Iron(III) acetylacetonate (Fe(acac) $\left.)_{3}, 97 \%\right)$, dibenzyl ether $(\geq 98 \%$, GC), 1,2-hexadecanediol, oleic acid ( $\geq 99 \%$, GC), oleylamine (OA) ( $\geq 98 \%)$, polyvinylpyrrolidone $\left(M_{\mathrm{w}} 40000\right)$, zinc nitrate hexahydrate $\left(\mathrm{Zn}\left(\mathrm{NO}_{3}\right)_{2} \cdot 6 \mathrm{H}_{2} \mathrm{O}\right)$, 2-methylimidazole (99\%) and dopamine hydrochloride were purchased from Sigma-Aldrich. Hexane, chloroform, ethanol were purchased from Beijing Chemical Works.

\subsection{Preparation of $\mathrm{OA}$-stabilized $\mathrm{Fe}_{3} \mathrm{O}_{4}$ nanoparticles}

OA-stabilized $\mathrm{Fe}_{3} \mathrm{O}_{4}$ NPs were prepared following the procedure of Sun et $a l^{24}$ The as-prepared NPs were precipitated with ethanol, washed several times and centrifuged at $7000 \mathrm{rpm}$ for 10 min. Then $\mathrm{Fe}_{3} \mathrm{O}_{4}$ NPs were re-dispersed in chloroform.

\subsection{Preparation of $\mathrm{Fe}_{3} \mathrm{O}_{4} / \mathrm{ZIF}-8$ nanostructures}

Before the encapsulation procedure, OA-stabilized $\mathrm{Fe}_{3} \mathrm{O}_{4}$ NPS were firstly modified with surfactant PVP. In brief, $\mathrm{Fe}_{3} \mathrm{O}_{4} \mathrm{NPS}$ were precipitated with ethanol, and centrifuged at $7000 \mathrm{rpm}$ for $10 \mathrm{~min}$. A solution of PVP $\left(M_{\mathrm{w}}=40000\right)$ in chloroform $(20 \mathrm{mg}$ $\mathrm{mL}^{-1}$ ) was used to re-dispersed the NPs. Then the mixture was kept for 24 hours, the PVP-modified $\mathrm{Fe}_{3} \mathrm{O}_{4}$ NPs were precipitated with hexane and collected by centrifugation at $7000 \mathrm{rpm}$ for $10 \mathrm{~min}$. The NPs were washed with chloroform for several times to remove the excess free PVP. And then the sample was re-dispersed in methanol.

In the encapsulation procedure, methanol was used as solvent. $10 \mathrm{~mL}$ solution of 2-methylimidazole (25 mM) and 10 $\mathrm{mL} 25 \mathrm{mM} \mathrm{Zn}\left(\mathrm{NO}_{3}\right)_{2} \cdot 6 \mathrm{H}_{2} \mathrm{O}$ (containing $1 \mathrm{~mL}$ PVP-stabilized $\mathrm{Fe}_{3} \mathrm{O}_{4}$ NPs methanol solution) were mixed and then allowed to react at room temperature for 1 hour without stirring. The product was collected by centrifugation at $5000 \mathrm{rpm}$ for $10 \mathrm{~min}$, washed several times with methanol, and final dispersed in 3.0 $\mathrm{mL}$ methanol.

\subsection{Preparation of $\mathrm{Fe}_{3} \mathrm{O}_{4} / \mathrm{PDA}$ NCs}

$3.0 \mathrm{~mL} \mathrm{Fe} \mathrm{O}_{4} / \mathrm{ZIF}-8$ methanol solution was mixed with $4.5 \mathrm{~mL}$ methanol and $1.5 \mathrm{~mL}$ dopamine $(20 \mathrm{mM}$ in methanol). The mixture was stirring and refluxing at $60^{\circ} \mathrm{C}$ for $12 \mathrm{~h}$, the color of which turned to black gradually. The product was collected by centrifugation at $6000 \mathrm{rpm}$ for $10 \mathrm{~min}$ and washed with methanol for several times, and freeze-drying overnight.

\subsection{Preparation of $\mathrm{Fe}_{3} \mathrm{O}_{4} / \mathrm{C} \mathrm{NCs}$}

$\mathrm{Fe}_{3} \mathrm{O}_{4} / \mathrm{PDA}$ NCs powder was thermal annealed at $550{ }^{\circ} \mathrm{C}$ under $\mathrm{N}_{2}$ flow with $3{ }^{\circ} \mathrm{C} \min ^{-1}$ for $4 \mathrm{~h}$.

\subsection{Electrochemical measurements}

The working electrodes were prepared by mixing the $\mathrm{Fe}_{3} \mathrm{O}_{4} / \mathrm{C}$ NCs, acetylene black, and poly(vinyldifluoride) (PVDF) at a weight ratio of $80: 10: 10$ in electrolyte of dimethyl carbonate (DMC) and ethylene carbonate (EC) $(1: 1 \mathrm{v} / \mathrm{v})$, pasting the mixture on pure $\mathrm{Cu}$ foil and dried at $100{ }^{\circ} \mathrm{C}$ under vacuum for $10 \mathrm{~h}$. The discharge-charge measurements were carried out at several different current densities between the cut off potentials of 0.01 and $3 \mathrm{~V}$ using Land CT2001A battery test system. Cyclic voltammogram (CV) measurements were performed on CHI750E electrochemical workstation.

\subsection{Characterization}

Transmission electron microscopy (TEM) images were collected on a Hitachi H-800 electron microscope operated at $200 \mathrm{kV}$ with a CCD camera. High-resolution TEM images and mapping images were recorded using a JEM-2100F electron microscope at an acceleration voltage of $200 \mathrm{kV}$ with a CCD camera. Scanning electron microscope (SEM) images were taken with a JEOL FESEM 6700F electron microscope with primary electron energy of $3 \mathrm{kV}$. The samples were sputtered with a thin layer of Pt prior to imaging. Inductively Coupled Plasma (ICP) results were conducted by OPTIMA 3300DV spectrometer. X-ray diffraction (XRD) analysis was performed by X-ray diffractometer, Model Rigaku Ru-200b, using a nickel-filtered $\mathrm{Cu} \mathrm{K} \alpha$ radiation and the data were collected from $10^{\circ}$ to $80^{\circ}$. X-ray photoelectron spectroscopic (XPS) analysis was done on an ESCALAB 250 spectrometer. Raman spectrum was recorded using a Horiba Jobin-Yvon micro Raman spectrometer, equipped with a microscope and a laser of $633 \mathrm{~nm}$ as the excitation source. $\mathrm{N}_{2}$ adsorptiondesorption measurements were conducted by Micromeritics ASAP 2010 instrument. The pore size distribution was calculated by the Barrett-Joyner-Halenda (BJH) method. And the specific surface area was calculated by using $\mathrm{BJH}$ and Brunauer-Emmett-Teller (BET) method. Hysteresis loop was tested by SQUID-VSM system. Magnetic measurements were performed using a SQUID magnetometer (SQUID-MPMS-XL) at $300 \mathrm{~K}$ by cycling the magnetic field between -30 and 30 kOe.

The main text of the article should appear here with headings as appropriate. 


\section{Results and discussion}

\subsection{Fabrication and regulation of $\mathrm{Fe}_{3} \mathrm{O}_{4} / \mathrm{C} \mathrm{NCs}$}

The synthesis process of dodecahedral $\mathrm{Fe}_{3} \mathrm{O}_{4} / \mathrm{C}$ NCs is schematically illustrated in Scheme 1. Firstly, OA-stabilized $\mathrm{Fe}_{3} \mathrm{O}_{4}$ nanoparticles (NPs), obtained through hydrothermal method, were firstly washed and modified with polyvinylpyrrolidone (PVP). ${ }^{24}$ The $\mathrm{Fe}_{3} \mathrm{O}_{4} / \mathrm{ZIF}-8$ nanostructure could be easily obtained by adding PVP- $\mathrm{Fe}_{3} \mathrm{O}_{4}$ NPs into the mixture of $\mathrm{Zn}\left(\mathrm{NO}_{3}\right)_{2}$ and 2methylimidazole. ${ }^{25}$ Then, dopamine (DA) was added to react with the as-prepared $\mathrm{Fe}_{3} \mathrm{O}_{4} / \mathrm{ZIF}-8$ and refluxed for $7 \mathrm{~h}$. During this process, the $\mathrm{Zn}^{2+}$ in $\mathrm{ZIF}-8$ was grabbed by DA via its catechol group, leading the disassembly of the template and releasing 2methylimidazole which triggered the polymerization of DA. ${ }^{13}$ Finally, the nanostructure got hollowed and $\mathrm{Fe}_{3} \mathrm{O}_{4}$ /polydopamine nanocages $\left(\mathrm{Fe}_{3} \mathrm{O}_{4} / \mathrm{PDA} \mathrm{NCs}\right)$ formed. After dried in vacuum and annealed at $550{ }^{\circ} \mathrm{C}$ under $\mathrm{N}_{2}$ flow $\left(3{ }^{\circ} \mathrm{C} \mathrm{min}{ }^{-1}\right.$ for 4 $\mathrm{h})$, the polymer shell of the PDA nanocages was transformed into a carbon layer and formed $\mathrm{Fe}_{3} \mathrm{O}_{4} / \mathrm{C} \mathrm{NCs}$. In our method, the hollow $\mathrm{C}$ nanocage was prepared without extra template removal, and the functionalization of the $\mathrm{C}$ nanocage, such as incorporating $\mathrm{Fe}_{3} \mathrm{O}_{4}$ NPs to the system is easily achieved through surfactant modification.

Electron microscopy measurements were conducted to monitor the product morphology changes in each preparation process. As shown in Fig. $\mathrm{S} 1, \dagger \mathrm{OA}$-stabilized $\mathrm{Fe}_{3} \mathrm{O}_{4}$ NPs were about $5 \mathrm{~nm} .{ }^{24}$ After forming $\mathrm{Fe}_{3} \mathrm{O}_{4} / \mathrm{ZIF}-8$, the nanostructure was about $350 \mathrm{~nm}$ with many $\mathrm{Fe}_{3} \mathrm{O}_{4}$ NPs loading in and on (Fig. 1A). The dodecahedral shape of $\mathrm{Fe}_{3} \mathrm{O}_{4} / \mathrm{ZIF}-8$ is very similar to that of pure ZIF-8, suggesting that incorporating functional nanoparticles have no obvious effects to the morphology of ZIF-8 nanostructure. With the reaction proceeding, the color of the solution turned gradually from brownish $\left(\mathrm{Fe}_{3} \mathrm{O}_{4} / \mathrm{ZIF}-8\right)$ to black, finally forming the hollow nanocages (Fig. 1B). The obtained $\mathrm{Fe}_{3} \mathrm{O}_{4} / \mathrm{PDA}$ NCs are $c a .364 \mathrm{~nm}$ with $c a .30 \mathrm{~nm}$ of PDA shell.

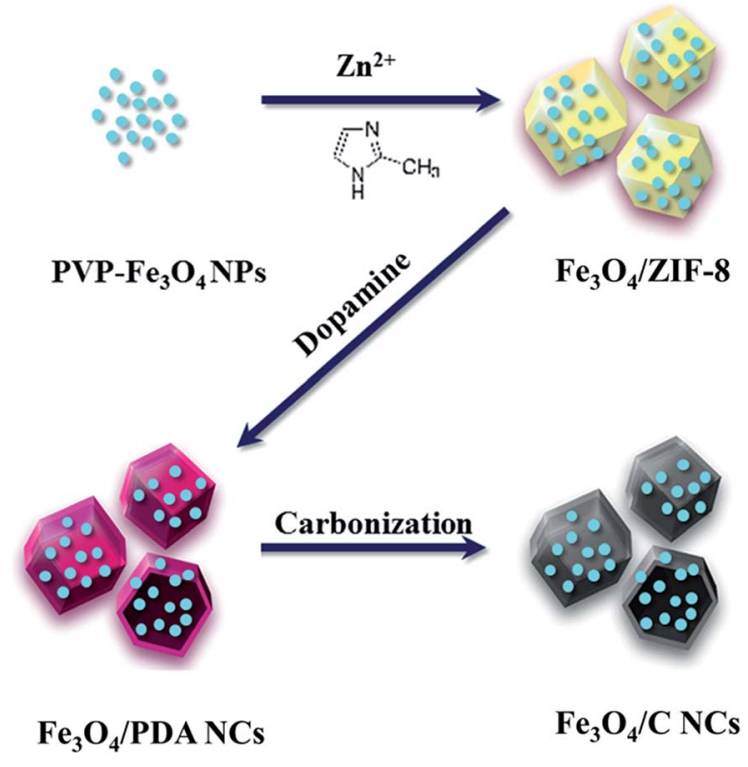

Scheme 1 Schematic illustration of the synthesis of $\mathrm{Fe}_{3} \mathrm{O}_{4} / \mathrm{C} \mathrm{NCs}$.
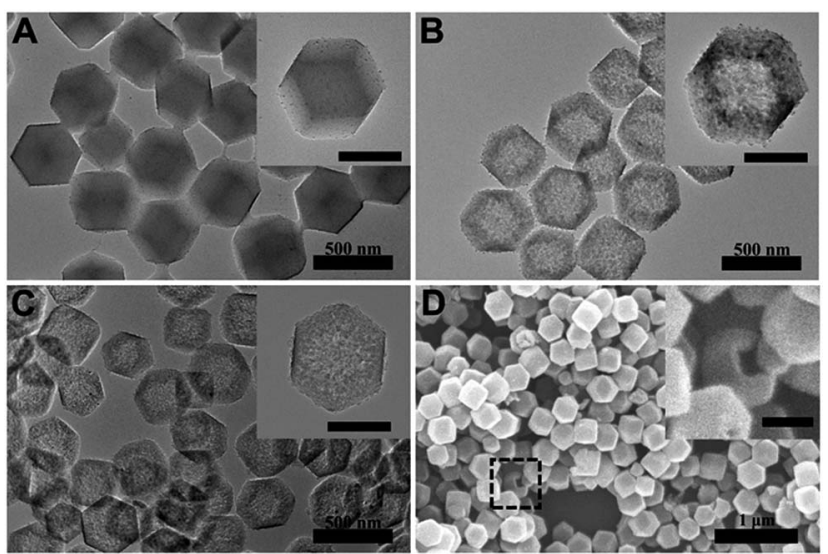

Fig. 1 TEM images of $\mathrm{Fe}_{3} \mathrm{O}_{4} / \mathrm{ZIF}-8(\mathrm{~A}), \mathrm{Fe}_{3} \mathrm{O}_{4} / \mathrm{PDA} \mathrm{NCs}(\mathrm{B}), \mathrm{Fe}_{3} \mathrm{O}_{4} / \mathrm{C}$ $\mathrm{NCS}(\mathrm{C})$ and SEM image of $\mathrm{Fe}_{3} \mathrm{O}_{4} / \mathrm{C}$ NCs (D). Insets: TEM images of $\mathrm{Fe}_{3} \mathrm{O}_{4} / \mathrm{ZIF}-8, \mathrm{Fe}_{3} \mathrm{O}_{4} / \mathrm{PDA} \mathrm{NCS}, \mathrm{Fe}_{3} \mathrm{O}_{4} / \mathrm{C} \mathrm{NCS}$ and SEM image of a broken $\mathrm{Fe}_{3} \mathrm{O}_{4} / \mathrm{C}$ NCs with high magnification. The scale bar in the insets is $200 \mathrm{~nm}$.

The hollowing process was monitored by TEM images in Fig. 2. With the time processing, the original solid $\mathrm{Fe}_{3} \mathrm{O}_{4} / \mathrm{ZIF}-8$ was firstly split to 'core-shell' structure (Fig. 2B). Then the 'core' part of the structure was getting smaller and smaller, and totally disappeared (Fig. 2C and D). $\mathrm{Fe}_{3} \mathrm{O}_{4} / \mathrm{C}$ NCs were prepared by further annealing $\mathrm{Fe}_{3} \mathrm{O}_{4}$ /PDA NCs under $\mathrm{N}_{2}$ flow. As shown in Fig. 1C, the obtained NCs maintained the original shape of ZIF8 nanostructures. SEM image also shows the appearance of $\mathrm{Fe}_{3} \mathrm{O}_{4} / \mathrm{C}$ NCs, which perfectly retained the dodecahedral morphology (Fig. 1D). The large hollow inner cavity observed from a typical broken structure also proves the formation of nanocages (inset in Fig. 1D). Optical photographs in Fig. S1B $\dagger$ shows that when placing a magnet, all the $\mathrm{Fe}_{3} \mathrm{O}_{4} / \mathrm{C}$ NCs the powder was attracted to the wall of glass vial, suggesting their good magnetism of the NCs. Moreover, the completely reversible $M(H)$ hysteresis curve suggests the superparamagnetic structure of $\mathrm{Fe}_{3} \mathrm{O}_{4} / \mathrm{C}$ NCs (Fig. S1D $\dagger$ ), which is consistent with $\mathrm{Fe}_{3} \mathrm{O}_{4}$ NPs we used (Fig. S1C $\dagger$ ). Elemental mapping measurements were also conducted to see the distribution of $\mathrm{Fe}_{3} \mathrm{O}_{4}$ in

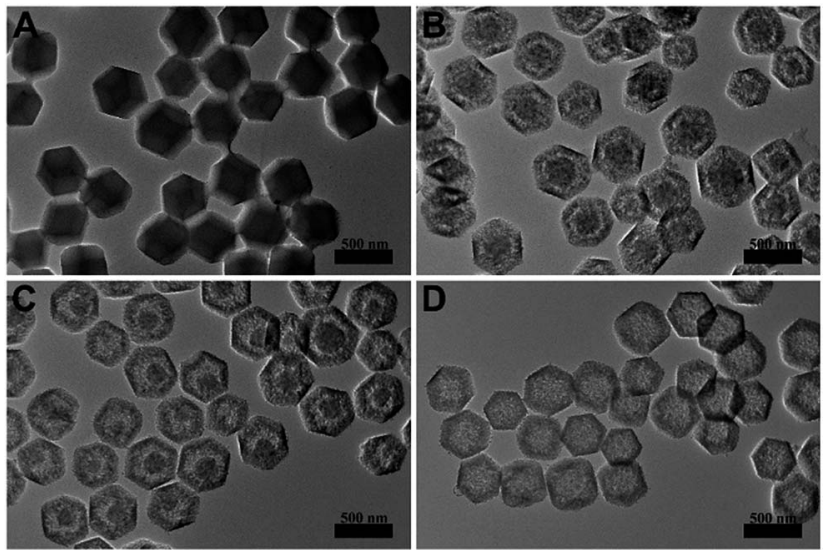

Fig. 2 TEM images of $\mathrm{Fe}_{3} \mathrm{O}_{4} / \mathrm{PDA} \mathrm{NCs}$ with the reaction time of $\mathrm{O} \mathrm{h}(\mathrm{A})$, $2 \mathrm{~h}(\mathrm{~B}), 4 \mathrm{~h}(\mathrm{C})$ and $7 \mathrm{~h}(\mathrm{D})$. 


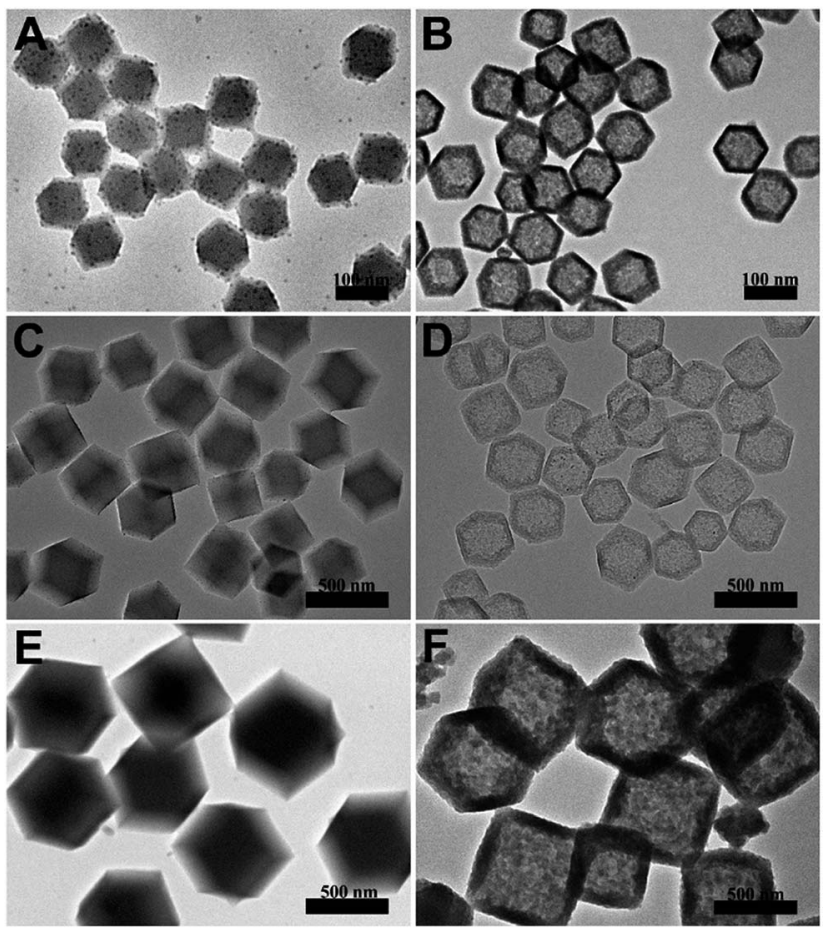

Fig. 3 TEM images of $\mathrm{Fe}_{3} \mathrm{O}_{4} / \mathrm{ZIF}-8$ nanostructure with different sizes (97 nm A, $350 \mathrm{~nm} \mathrm{C}$ and $574 \mathrm{~nm} \mathrm{E}$ ) and the corresponding $\mathrm{Fe}_{3} \mathrm{O}_{4} / \mathrm{C}$ NCs $(90 \mathrm{~nm} \mathrm{~B}, 332 \mathrm{~nm} \mathrm{D}$ and $561 \mathrm{~nm} \mathrm{~F})$.

both $\mathrm{Fe}_{3} \mathrm{O}_{4} /$ PDA NCs and $\mathrm{Fe}_{3} \mathrm{O}_{4} / \mathrm{C}$ NCs. As shown in Fig. $\mathrm{S} 2, \uparrow$ the element $\mathrm{C}$ presents a hollow dodecahedral shape and distributes throughout the structure (red), while Fe (green) major distributed on the backbone of the carbon nanocages. All these results prove that $\mathrm{Fe}_{3} \mathrm{O}_{4}$ NPs are retained in the final products even experiencing hollowing process. Inductively coupled plasma (ICP) results present the content of metallic elements in Table $\mathrm{S} 2, \uparrow$ suggesting the loading capacity of $\mathrm{Fe}_{3} \mathrm{O}_{4}$ could reach $20.3 \%$ of the $\mathrm{Fe}_{3} \mathrm{O}_{4} / \mathrm{C}$ NCs. Series of $\mathrm{Fe}_{3} \mathrm{O}_{4} / \mathrm{C}$ NCs were obtained by precisely controlling the reaction condition. For example, the size of the NCs could be regulated by changing that of ZIF-8 templates. As shown in Fig. 3, $\mathrm{Fe}_{3} \mathrm{O}_{4} / \mathrm{C}$ NCs from down-to$100 \mathrm{~nm}(90 \mathrm{~nm})$ to over $500 \mathrm{~nm}(561 \mathrm{~nm})$ could be achieved. Moreover, the loading capacity of the $\mathrm{Fe}_{3} \mathrm{O}_{4}$ NPs could also be modulated (Fig. S3 $\dagger$ ) and the functional nanoparticles is replaceable. These controllable nanocages may meet the demands of application in variety of fields by choosing suitable sizes and functionalities in the future.

\subsection{Characterization of $\mathrm{Fe}_{3} \mathrm{O}_{4} / \mathrm{C} \mathrm{NCs}$}

Raman spectroscopy is displayed to characterize the nature of $\mathrm{Fe}_{3} \mathrm{O}_{4} / \mathrm{C}$ NCs (Fig. 4). Two major peaks at ca. 1336 and 1580 $\mathrm{cm}^{-1}$ are corresponding to the ' $\mathrm{D}$ ' and ' $\mathrm{G}$ ' bands of carbon materials, respectively. ${ }^{22}$ The intensity ratio of these two bands $\left(I_{\mathrm{D}} / I_{\mathrm{G}}\right)$ reaches 1.47 , suggesting that the presence of carbon in the NCs is in the form of amorphous structure. Besides, the peaks at ca. 310, 534, and $626 \mathrm{~cm}^{-1}$ are assigned to $\mathrm{Fe}_{3} \mathrm{O}_{4} \mathrm{NPs}$, meanwhile ca. 426, 559, and $1100 \mathrm{~cm}^{-1}$ belong to $\mathrm{ZnO}$, which is
A

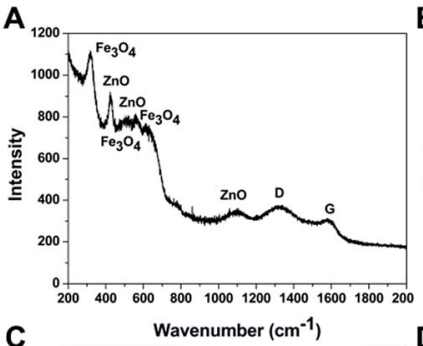

B

C
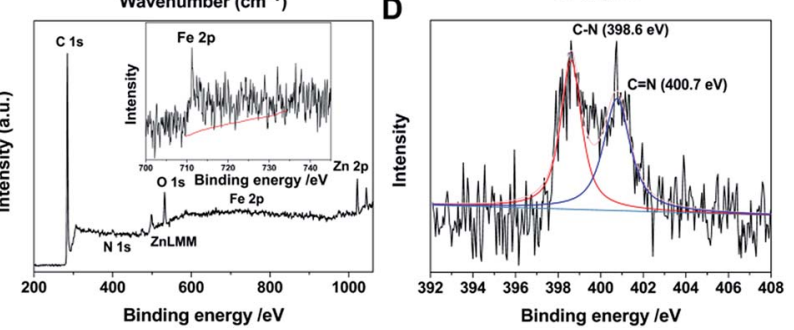

Fig. 4 Raman spectrum of $\mathrm{Fe}_{3} \mathrm{O}_{4} / \mathrm{C} \mathrm{NCS} \mathrm{(A),} \mathrm{XRD} \mathrm{patterns} \mathrm{of} \mathrm{Fe}_{3} \mathrm{O}_{4}$ (black line) and $\mathrm{Fe}_{3} \mathrm{O}_{4} / \mathrm{C} \mathrm{NCs}$ (red line) (B), XPS spectrum (C) and $\mathrm{N} 1 \mathrm{~s}$ spectrum (D) of $\mathrm{Fe}_{3} \mathrm{O}_{4} / \mathrm{C} \mathrm{NCs}$.

further proved by the results of powder X-ray diffraction (XRD) measurements in Fig. 4B. ${ }^{26,27} \mathrm{Fe}_{3} \mathrm{O}_{4} / \mathrm{C}$ NCs exhibit strong wurtzite patterns of $\mathrm{ZnO}$ (red line, JCPDS card number 36-1451), which is formed during the annealing process, and the content is $37.4 \%$ (Table $\mathrm{S} 2 \dagger$ ). ${ }^{28}$ HRTEM also prove the crystallinity of $\mathrm{ZnO}$ (Fig. S4 $\dagger$ ). Comparing to $\mathrm{Fe}_{3} \mathrm{O}_{4} / \mathrm{PDA}$ NCs, no obvious structure changes were observed in $\mathrm{Fe}_{3} \mathrm{O}_{4} / \mathrm{C}$ NCs, suggesting that the existence of $\mathrm{ZnO}$ has no effect on the structure of our system. It is worth noting that only a weak peak $\left(\mathrm{ca} .35^{\circ}\right)$ belongs to $\mathrm{Fe}_{3} \mathrm{O}_{4}$ (green dashed circle, JCPDS no. 65-3107) was observed in the pattern. This is due to the originally low intensity of pure $\mathrm{Fe}_{3} \mathrm{O}_{4}$ (black line), together with the shielding effect of the $\mathrm{ZnO}^{22}$ A diffuse scattering peak observed at around $20^{\circ}$ is attributed to the amorphous form of carbon nanocages, which is consisted with the Raman spectroscopy results (Fig. 4A). The chemical composition of the $\mathrm{Fe}_{3} \mathrm{O}_{4} / \mathrm{C}$ NCs was characterized by $\mathrm{X}$-ray photoelectron spectroscopy (XPS). As shown in Fig. 4C, an overall XPS spectrum of $\mathrm{Fe}_{3} \mathrm{O}_{4} / \mathrm{C}$ NCs indicates the presence of $\mathrm{C}, \mathrm{Fe}, \mathrm{O}, \mathrm{N}$ and $\mathrm{Zn}$ elements in the NCs, and the peak at $711.2 \mathrm{eV}$ can be assigned to the Fe $2 \mathrm{p}_{3 / 2}$, referencing to the standard XPS spectrum for $\mathrm{Fe}_{3} \mathrm{O}_{4} \cdot{ }^{29}$ In the high-resolution $\mathrm{N}$ 1s spectrum (Fig. 4D), two peaks observed at $\sim 398.6 \mathrm{eV}$ and $400.7 \mathrm{eV}$ are identified to $\mathrm{C}-\mathrm{N}$ and $\mathrm{C}=\mathrm{N}$, indicating $\mathrm{N}$ is doped in the structure of carbon nanocages. It is derived from the amine group in the PDA, which also serves as carbon source in our system, and the doping content is $2.8 \%$, as shown in Table S1. $\dagger$

Such doping is beneficial to improve the electrical conductivity and surface hydrophilicity, further increasing the potential application of $\mathrm{Fe}_{3} \mathrm{O}_{4} / \mathrm{C}$ NCs in electrochemistry field. During the formation of $\mathrm{Fe}_{3} \mathrm{O}_{4} / \mathrm{PDA} \mathrm{NCs}$, the disassembling process of ZIF-8 template demonstrates the permeability of PDA shell for the mass diffusion through the interstices (Fig. 2). After the carbonization process, the porous property of $\mathrm{Fe}_{3} \mathrm{O}_{4} / \mathrm{C}$ NCs was investigated through $\mathrm{N}_{2}$ adsorption-desorption isotherm (Fig. 5). The nanocages display a typical IV-type isotherm, indicating the presence of mesopores. An obvious H3-type 


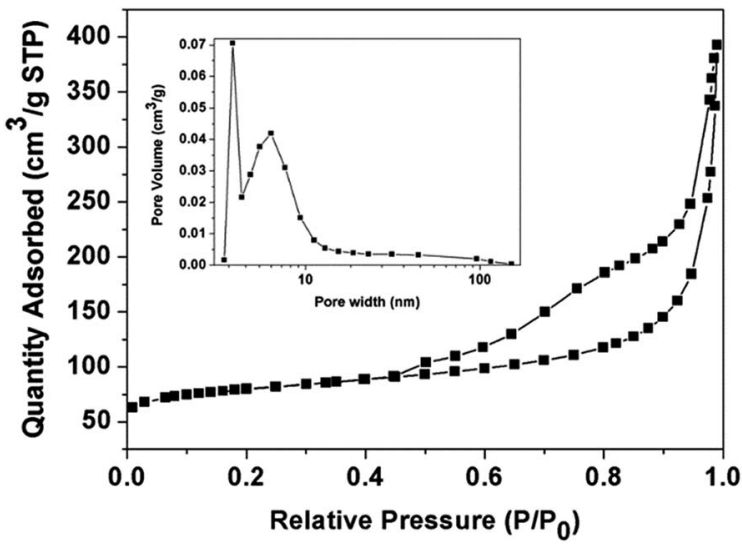

Fig. 5 Nitrogen adsorption-desorption isotherms of $\mathrm{Fe}_{3} \mathrm{O}_{4} / \mathrm{C}$ NCs. Inset: $\mathrm{BJH}$ desorption $\mathrm{dV} / \mathrm{d}$ w pore width of $\mathrm{Fe}_{3} \mathrm{O}_{4} / \mathrm{C} \mathrm{NCs}$.

hysteresis loop is observed after $P / P_{0}$ reaching 0.5 , due to the adsorption of $\mathrm{N}_{2}$ in the inner cavities of $\mathrm{Fe}_{3} \mathrm{O}_{4} / \mathrm{C} \mathrm{NCs.}{ }^{22}$ The BET surface area is $383.9 \mathrm{~m}^{2} \mathrm{~g}^{-1}$, and the pore sizes of the nanocages are mainly focus on $c a .3 .8 \mathrm{~nm}$ and $6.2 \mathrm{~nm}$, deriving from the formation of nanocage and the gas release during the carbonization of the polymer shell. Such relatively high surface area will provide highly permeable for mass diffusion of electrolyte, improving the interaction between the nanocages and solution.

\subsection{Lithium storage properties of $\mathrm{Fe}_{3} \mathrm{O}_{4} / \mathrm{C} \mathrm{NCs}$}

The $\mathrm{Fe}_{3} \mathrm{O}_{4}$ was chosen to incorporate in the nanocages because it has been regarded as one of promising anode materials for rechargeable LIBs. It possesses high theoretical capacity ( $\sim 927$ $\mathrm{mA} \mathrm{h} \mathrm{g}^{-1}$ ), natural abundance and nontoxicity. ${ }^{26,30-32}$ Motivated by such intriguing structure, we evaluated the electrochemical properties of the obtained $\mathrm{Fe}_{3} \mathrm{O}_{4} / \mathrm{C}$ NCs. Fig. 6A shows the representative cyclic voltammograms (CVs) of the sample between $10 \mathrm{mV}$ and $3 \mathrm{~V}$ at a scan rate of $0.1 \mathrm{mV} \mathrm{s}^{-1}$. A relatively weak reduction peak is observed around $0.1 \mathrm{~V}$, which responses to the multistep reduction processes from $\mathrm{ZnO}$ to $\mathrm{Zn}^{0}$ and the generation of $\mathrm{Li}-\mathrm{Zn}$ alloy. ${ }^{33,34}$ The peak around $0.5 \mathrm{~V}$ in the first scan of the electrode is attributed to the formation of the solid electrolyte interphase (SEI) layer. The CV curves at the second and third cycles show a broad peak at $0.5-1.0 \mathrm{~V}$, corresponding to the reduction of $\mathrm{ZnO}$ and $\mathrm{Fe}_{3} \mathrm{O}_{4}$ and the formation of amorphous $\mathrm{Li}_{2} \mathrm{O} .^{33}$ The reduction peaks at $\sim 0.9 \mathrm{~V}$ in the first cycle and $\sim 0.83 \mathrm{~V}$ at $2^{\text {nd }}$ scan are ascribed to the reduction of $\mathrm{Fe}_{3} \mathrm{O}_{4}$ and the formation of SEI layer. There are three adjacent small oxidation peaks appearing below $1 \mathrm{~V}$ in the following anodic scan, which may be indicated as the multistep dealloying process of $\mathrm{Li}-\mathrm{Zn}$ alloy $\left(\mathrm{LiZn}, \mathrm{Li}_{2} \mathrm{Zn}, \mathrm{LiZn}_{2}\right.$, and $\left.\mathrm{Li}_{2} \mathrm{Zn}_{5}\right){ }^{33}$ In addition, the smooth and broad oxidation peak around 1.31.7 $\mathrm{V}$ may be ascribed to the decomposition of $\mathrm{Li}_{2} \mathrm{O}$ and the oxidation of $\mathrm{Fe}^{0}{ }^{25}$ The little changes in these oxidation peaks indicate a good reversibility of the electrochemical reaction.

The charge-discharge voltage profiles of $\mathrm{Fe}_{3} \mathrm{O}_{4} / \mathrm{C}$ NCs with different cycles at $100 \mathrm{~mA} \mathrm{~g}^{-1}$ in the voltage range of $0.01-3.0 \mathrm{~V}$ are shown in Fig. 6B. In the first cycle, $\mathrm{Fe}_{3} \mathrm{O}_{4} / \mathrm{C}$ NCs exhibit an initial discharge capacity of $1370 \mathrm{~mA} \mathrm{~h} \mathrm{~g}^{-1}$ and a charge capacity of 789
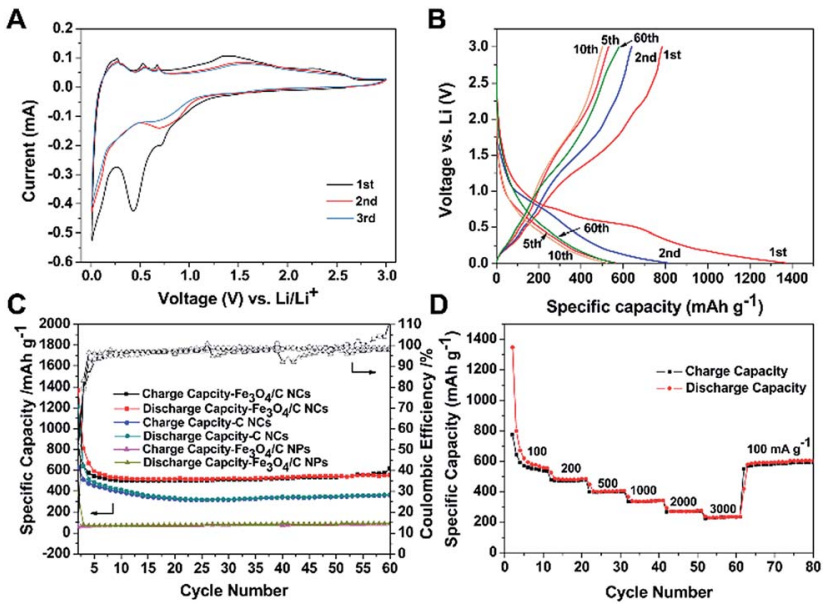

Fig. 6 Cyclic voltammograms of $\mathrm{Fe}_{3} \mathrm{O}_{4} / \mathrm{C} \mathrm{NCs}$ between $10 \mathrm{mV}$ and $3 \mathrm{~V}$ at a scan rate of $0.1 \mathrm{mV} \mathrm{s}^{-1}(\mathrm{~A})$, charge-discharge voltage profiles (B), cycling performance and the corresponding $\mathrm{CE}$ of the $\mathrm{Fe}_{3} \mathrm{O}_{4} / \mathrm{C}$ $\mathrm{NCs}$ compared to $\mathrm{CNCs}$ and solid $\mathrm{Fe}_{3} \mathrm{O}_{4} / \mathrm{C} \mathrm{NPs}$ at $100 \mathrm{~mA} \mathrm{~g}^{-1}$ (C) and rate capability of the $\mathrm{Fe}_{3} \mathrm{O}_{4} / \mathrm{C} \mathrm{NCs}$ at various current rates (D).

$\mathrm{mA} \mathrm{h} \mathrm{g}^{-1}$, with an initial coulombic efficiency (CE) of $57.6 \%$ based on the total mass of the sample. The capacity loss in the first cycle may be attributed to the irreversible processes such as the formation of SEI layer and amorphous $\mathrm{Li}_{2} \mathrm{O}$, trapped $\mathrm{Li}^{+}$in the inner cavity of the $\mathrm{Fe}_{3} \mathrm{O}_{4} / \mathrm{C}$ NCs and the decomposition of the electrolyte, etc. ${ }^{24,25}$ Fig. 6C shows the cycling performance and the corresponding $\mathrm{CE}$ of the $\mathrm{Fe}_{3} \mathrm{O}_{4} / \mathrm{C}$ NCs. The first charge and discharge capacity are 789-1370 $\mathrm{mA} \mathrm{h} \mathrm{g}^{-1}$ and gradually remain at $584 \mathrm{~mA} \mathrm{~h} \mathrm{~g}^{-1}$ with the prolonging of cycling. Moreover, its CE after 4 cycles maintains at about $100 \%$. The rate capability of the $\mathrm{Fe}_{3} \mathrm{O}_{4} /$ C NCs was also characterized to evaluate their electrochemical performance. As shown in Fig. 6D, with the increasing of the current density $\left(100,200,500,1000,2000,3000 \mathrm{~mA} \mathrm{~g}^{-1}\right)$, the $\mathrm{Fe}_{3} \mathrm{O}_{4} / \mathrm{C}$ NCs can still deliver reversible capacities of 574, 485, 405, 338, 269 and $235 \mathrm{~mA} \mathrm{~h} \mathrm{~g}{ }^{-1}$, respectively. Remarkably, when the current density turns back to $100 \mathrm{~mA} \mathrm{~g}^{-1}$, a reversible capacity of $603 \mathrm{~mA} \mathrm{~h} \mathrm{~g}^{-1}$ can be obtained. To demonstrate the advantage of $\mathrm{Fe}_{3} \mathrm{O}_{4} / \mathrm{C}$ NCs, the cycling performance of carbon nanocages and solid $\mathrm{Fe}_{3} \mathrm{O}_{4} / \mathrm{C}$ nanoparticles $\left(\mathrm{Fe}_{3} \mathrm{O}_{4} / \mathrm{C}\right.$ NPs with the same composition with $\mathrm{Fe}_{3} \mathrm{O}_{4} / \mathrm{C}$ NCs) is also investigated under the same conditions for comparison. As shown in Fig. 6C, a capacity of $c a$. $367 \mathrm{~mA} \mathrm{~h} \mathrm{~g}^{-1}$ is delivered by C NCs, while only ca. $98 \mathrm{~mA} \mathrm{~h} \mathrm{~g}^{-1}$ of the $\mathrm{Fe}_{3} \mathrm{O}_{4} / \mathrm{C}$ NPs, showing much lower cycling performance. The comparison of the cycling performance shows the superiority of both incorporating $\mathrm{Fe}_{3} \mathrm{O}_{4}$ NPs and the specific hollow structure in $\mathrm{Fe}_{3} \mathrm{O}_{4} / \mathrm{C}$ NCs. Moreover, our $\mathrm{Fe}_{3} \mathrm{O}_{4} / \mathrm{C}$ NCs have shown obviously improved electrochemical performance compared to the $\mathrm{C}$ NCs (Fig. S5 $\dagger$ ). The status of the $\mathrm{Fe}_{3} \mathrm{O}_{4} / \mathrm{C}$ NCs electrode after cycling was characterized by SEM. As shown in Fig. S6A, $\uparrow$ no obvious changes in morphology of $\mathrm{Fe}_{3} \mathrm{O}_{4} / \mathrm{C}$ NCs after cycling, and the hollow interior observed in the typical broken particle prove the nanostructures were $\mathrm{Fe}_{3} \mathrm{O}_{4} / \mathrm{C}$ NCs (Fig. $\mathrm{S} 6 \mathrm{~B} \dagger$ ), suggesting that our hollow nanocages can effectively relive the volume expansion, stabilizing and preserving the integrity of $\mathrm{Fe}_{3} \mathrm{O}_{4} / \mathrm{C}$ NCs during the charge-discharge process. 
The good cycling performance of the $\mathrm{Fe}_{3} \mathrm{O}_{4} / \mathrm{C}$ NCs is benefitted from their specific structure, which effectively integrated advantages of each component. Firstly, the mesoporous wall and large inner cavity of carbon nanocages greatly enlarge the surface sites, increase the electrochemical reaction area, shorten the diffusion pathway of $\mathrm{Li}$ ions and allow to buffer the volume change during the charge-discharge process. Secondly, the incorporated $\mathrm{Fe}_{3} \mathrm{O}_{4}$ NPs and ZnO formed in carbonization display positive contributions in the charge-discharge process. Moreover, $\mathrm{Fe}_{3} \mathrm{O}_{4} \mathrm{NPs}$ are uniformly distributed in carbon nanocages through this method, which fully take their advantages of nanoscaled and large surface area. These synergistic effects of nanocages and $\mathrm{Fe}_{3} \mathrm{O}_{4}$ contribute to the desired performance of $\mathrm{Fe}_{3} \mathrm{O}_{4} / \mathrm{C}$ NCs, indicating their promising application in LIBs.

\section{Conclusions}

In summary, a distinct carbon nanocages modifies with $\mathrm{Fe}_{3} \mathrm{O}_{4} \mathrm{NPs}$ incorporated has been constructed successfully by using ZIF-8 as template and PDA as carbon source. The morphology of $\mathrm{Fe}_{3} \mathrm{O}_{4} / \mathrm{C}$ NCs retained the dodecahedral shape of ZIF-8, and series of NCs can be prepared by precisely controlling the reaction conditions. Since the distinct properties of hollow carbon nanocages and functional $\mathrm{Fe}_{3} \mathrm{O}_{4} \mathrm{NPs}$, the lithium storage properties of the obtained $\mathrm{Fe}_{3} \mathrm{O}_{4} / \mathrm{C}$ NCs are studied and display stable capacity retention and cycling performance even at high rates of $3000 \mathrm{~mA}$ $\mathrm{g}^{-1}$ in comparison with C NCs, suggesting their promising application in LIBs. The nanocages we fabricated may open up a new platform for preparation of various carbon-based hollow nanostructures with functionalities.

\section{Acknowledgements}

This work was supported by NSFC (81320108011), Major Project of the Ministry of Science and Technology of China (2016YFC1102800) and NSFC (54133003).

\section{Notes and references}

1 X. Wang, J. Feng, Y. Bai, Q. Zhang and Y. Yin, Chem. Rev., 2016, 116, 10983.

2 X. Lou, L. A. Archer and Z. Yang, Adv. Mater., 2008, 20, 3987.

3 Z. Luo, X. Ding, Y. Hu, S. Wu, Y. Xiang, Y. Zeng, B. Zhang, H. Yan, H. Zhang, L. Zhu, J. Liu, J. Li, K. Cai and Y. Zhao, ACS Nano, 2013, 7, 10271.

4 C. J. Ochs, H. Hong, G. K. Such, J. Cui, A. Postma and F. Caruso, Chem. Mater., 2011, 23, 3141.

5 Z. Wang and X. Lou, Adv. Mater., 2012, 24, 4124.

6 G. Zhang, H. B. Wu, T. Song, U. Paik and X. W. Lou, Angew. Chem., Int. Ed., 2014, 53, 12590.

7 A. O. Moughton and R. K. O'Reilly, J. Am. Chem. Soc., 2008, 130, 8714.

8 C. M. Cobley and Y. N. Xia, Mater. Sci. Eng., R, 2010, 70, 44.

9 O. Shchepelina, V. Kozlovskaya, S. Singamaneni, E. Kharlampieva and V. V. Tsukruk, J. Mater. Chem., 2010, 20, 6587.
10 G. Zhang, H. Wu, T. Song, U. Paik and X. Lou, Angew. Chem., Int. Ed., 2014, 53, 12590.

11 L. Shen, L. Yu, X. Yu, X. Zhang and X. Lou, Angew. Chem., Int. Ed., 2015, 54, 1868.

12 X. Yu, L. Yu, L. Shen, X. Song, H. Chen and X. Lou, Adv. Funct. Mater., 2014, 24, 7440.

13 S. Xiang, D. Wang, K. Zhang, W. Liu, C. Wu, Q. Meng, H. Sun and B. Yang, Chem. Commun., 2016, 52, 10155-10158.

14 G. Jeong, Y.-U. Kim, H. Kim, Y.-J. Kim and H.-J. Sohn, Energy Environ. Sci., 2011, 4, 1986.

15 M. Nie, D. Chalasani, D. P. Abraham, A. Bose and B. L. Bose, J. Phys. Chem. C, 2013, 117, 1257.

16 K. Xu and A. V. Cresce, J. Mater. Chem., 2011, 21, 9849.

17 B. Li, Y. Wang, H. Rong, Y. Wang, J. Liu, L. Xing, M. Xu and W. Li, J. Mater. Chem. A, 2013, 1, 12954.

18 C. Ding, Y. Zeng, L. Cao, L. Zhao and Y. Zhang, J. Mater. Chem. A, 2016, 4, 5898.

19 F. Zheng, Y. Yang and Q. Chen, Nat. Commun., 2014, 5, 5261.

20 Y. Yang, J. Li, D. Chen and J. Zhao, A facile electrophoretic deposition route to the $\mathrm{Fe}_{3} \mathrm{O}_{4} / \mathrm{CNTs} / \mathrm{rGO}$ composite electrode as a binder-free anode for lithium ion battery, ACS Appl. Mater. Interfaces, 2016, 8, 26730-26739.

21 F. Maronia, S. Gabriellia, A. Palmieria, E. Marcantonia, F. Croceb and F. Nobili, High cycling stability of anodes for lithium-ion batteries based on $\mathrm{Fe}_{3} \mathrm{O}_{4}$ nanoparticles and poly(acrylic acid) binder, J. Power Sources, 2016, 332, 79-87.

22 Q. Meng, F. Zhang, L. Wang, S. Xiang, S. Zhu, G. Zhang, K. Zhang and B. Yang, Facile fabrication of mesoporous Ndoped $\mathrm{Fe}_{3} \mathrm{O}_{4} @ \mathrm{C}$ nanospheres as superior anodes for $\mathrm{Li}$-ion batteries, RSC Adv., 2014, 4, 713-716.

23 M. Huang, K. Mi, J. Zhang, H. Liu, T. Yu, A. Yuan, Q. Kong and S. Xiong, J. Mater. Chem. A, 2017, 5, 266.

24 S. Sun and H. Zeng, J. Am. Chem. Soc., 2012, 124, 8204.

25 G. Lu, S. Li, Z. Guo, O. K. Farha, B. G. Hauser, X. Qi, Y. Wang, X. Wang, S. Han, X. Liu, H. Zhang, Q. Zhang, X. Chen, J. Ma, S. C. J. Loo, W. D. Wei, Y. Yang, J. T. Hupp and F. W. Huo, Nat. Chem., 2012, 4, 310.

26 C. Ding, Y. Zeng, L. Cao, L. Zhao and Y. Zhang, J. Mater. Chem. A, 2016, 4, 5898.

27 J. L. Santosa, T. R. Reinaa, S. Ivanovaa, M. A. Centenoa and J. A. Odriozola, Appl. Catal., B, 2017, 201, 310.

28 P. Li, Z. Wei, T. Wu, Q. Peng and Y. Li, J. Am. Chem. Soc., 2011, 133, 5660.

29 Z. Li, M. Jaroniec, P. Papakonstantinou, J. M. Tobin, U. Vohrer, S. Kumar, G. Attard and J. D. Holmes, Chem. Mater., 2007, 19, 3349.

30 Z. Xiao, Y. Xia, Z. Ren, Z. Liu, G. Xu, C. Chao, X. Li, G. Shen and G. Han, J. Mater. Chem., 2012, 22, 20566.

31 S. K. Behera, J. Power Sources, 2011, 196, 8669.

32 Y. Deng, Q. Zhang, Z. Shi, L. Han, F. Peng and G. Chen, Electrochim. Acta, 2012, 76, 495.

33 Y. Wang, X. Jiang, L. Yang, N. Jia and Y. Ding, ACS Appl. Mater. Interfaces, 2014, 6, 1525.

34 M. Ahmad, Y. Shi, A. Nisar, H. Sun, W. Shen, W. Miao and J. Zhu, J. Mater. Chem., 2011, 21, 7723. 